\title{
Editorial Comment: The times they are a-changin'
}

\author{
Lucas Venter \\ Director: Research support, North West University, and \\ Professor Extraordinarius: University of South Africa
}

During the process of typesetting this edition of SACJ, the lyrics of an old song by Bob Dylan kept on popping up in my thoughts:

Then you better start swimmin'

Or you'll sink like a stone

For the times they are a-changin'. ${ }^{1}$

As was announced in SACJ44, the AGM of SAICSIT decided that as from issue 45 , SACJ will only be published online as an open-source journal. No printed copy of SACJ will be produced. This form of publication is not new. In fact, many journals have for a long time been published in this format. For journals in Computing, this is now one of the standards, if not the norm.

Just as I started the process of typesetting this edition, Derrick Kourie, the previous editor of SACJ, asked me for an input to a paper that is to be published in the Transactions of the Royal Society of South Africa. The paper contains a table with the 10 most cited papers that appeared in SACJ. Only 3 of these had been published since 2000, the last (with 17 citations) published in 2003.

This reminded me of the concluding remark in a paper by by Paula Kotze and Alta van der Merwe ${ }^{2}$, who, in a sense, pose the same problem. They mention that their paper did not try to determine the validity of SACJ as a representative of the research landscape in Computing in South Africa. After making this statement, they then pose a number of questions. The tone of the questions seems to imply that they believe the contrary to be true. They conclude with this question:

If it is representing the research landscape, how can the new editor make sure that it stays representative and become an even stronger voice of computing in South Africa?

A brief visit to the NRF database of rated researchers reveals at least $11 \mathrm{~B}$-rated scientists working in Computing, and at least 33 with a C-rating. Hence, the work done by the South African community is recognised as relevant; at least the $11 \mathrm{~B}$ 's

enjoy considerable international recognition by their peers for the high quality and impact of their recent research outputs ${ }^{3}$.

The conclusion to be drawn is that the South African research community may be relatively small, but it is not unknown internationally, and not irrelevant.

\footnotetext{
${ }^{1}$ Bob Dylan 1963, 1968 Warner Bros. Inc Renewed 1991 Special Rider Music

${ }^{2}$ P Kotze and A van der Merwe., 2009. The Research Foci of Computing Research in South Africa as Reflected by Publications in the South African Computer Journal, SACJ44.

${ }^{3}$ http://evaluation.nrf.ac.za/
}

One would also need to assume that the rated scientists define the Computing research landscape in South Africa; they are after all the research leaders. One obvious way of doing this would be to also publish locally. The following table shows the publication record of the various categories of rated scientists in SACJ38 (June 2007) to SACJ44 (December 2009), which contained a total of 60 refereed papers.

\begin{tabular}{|r|c|c|c|c|c|c|c|c|}
\hline & 38 & 39 & 40 & 41 & 42 & 43 & 44 & Total \\
\hline $\mathrm{B}$ & 0 & 0 & 0 & 1 & 1 & 0 & 1 & 3 \\
\hline $\mathrm{C}$ & 2 & 1 & 7 & 3 & 9 & 1 & 1 & 24 \\
\hline $\mathrm{L} / \mathrm{Y}$ & 0 & 0 & 3 & 0 & 1 & 1 & 1 & 6 \\
\hline Total & 2 & 1 & 10 & 4 & 11 & 2 & 3 & 33 \\
\hline
\end{tabular}

As a group, the $\mathrm{C}$ and $\mathrm{L} / \mathrm{Y}$ categories have a reasonable publication record in SACJ, and one can hence conclude that SACJ is to some extent representative of the research landscape in South Africa.

The B-rated scientists do not publish in SACJ; the three papers published since June 2007 had only two different Brated authors. Many of them did publish in SACJ before achieving the $\mathrm{B}$ rating. Clearly, these researchers are now recognised internationally, because they publish in forums that are read internationally. This argument is often concluded with a remark that SACJ is not visible internationally.

There is however a counterargument to be made. The Brated scientists are recognised internationally for making an impact in their fields. Hence, the international community will necessarily want to keep up with the work done by these people, if it is reasonably accessible. And SACJ is now accessible; it is freely available online. These scientists can provide the stimulus for researchers internationally to want to read SACJ, thereby also exposing the work of the $\mathrm{C}$ and $\mathrm{L} / \mathrm{Y}$ scientists to the international community.

To answer the question posed by Paula Kotze and Alta van der Merwe: SACJ now provides a platform for all South African researchers to publish in a journal which is freely available internationally. The leading South African scientists can now take up the challenge to attract this community to SACJ. Whether they will do this remains to be seen. Or, as Bob Dylan put it many years ago,

The answer my friend is blowin' in the wind. 